\title{
Feasibility study for the microseismic monitoring of the natural gas reservoir of "Sant'Alberto" (Po Plain, Italy)
}

\author{
Simona Carannante ${ }^{\star 1}$, Ezio D’Alema ${ }^{1}$, Sara Lovati ${ }^{1}$, Marco Massa ${ }^{1}$, Paolo Augliera ${ }^{1}$, \\ Gianlorenzo Franceschina ${ }^{1}$ \\ ${ }^{1}$ Istituto Nazionale di Geofisica e Vulcanologia, Sezione di Milano, Milan, Italy
}

\author{
Article history \\ Received July 14, 2016; accepted November 30, 2016. \\ Subject classification: \\ Induced seismicity, Microseismic monitoring, Seismic network, Ambient noise.
}

\begin{abstract}
In this paper we present a feasibility study for the surface seismic monitoring of the "Sant'Alberto" gas reservoir (Po Plain, Northern Italy). The project was commissioned to INGV in the framework of the activities planned by the oil \& gas E\&P company PoValley Energy (PVE), aiming to exploit the underground deposit. After estimating the ambient seismic noise of the area, we hypothesized a microseismic network composed of five stations installed in a $8.0 \times 8.0 \mathrm{~km}^{2}$ area centered on the surface projection of the reservoir. Moreover, due to the high noise levels observed, we also considered the possible installation of a borehole station at $200 \mathrm{~m}$ depth. Detection and localization thresholds were estimated by comparing the simulated power spectral density of hypothetical seismic sources located in the crustal volume surrounding the reservoir, with the mean power spectra of the ambient seismic noise observed (or hypothesized) at each station-site. Two crustal volumes for the earthquakes detection were considered: the inner domain of detection, DI $\left(8.6 \times 8.6 \times 4.0 \mathrm{~km}^{3}\right)$, within which we should ensure the highest network performance, and the extended domain of detection, $D E\left(18.6 \times 18.6 \times 9.0 \mathrm{~km}^{3}\right)$. After estimating the background level of ambient seismic noise, simulations show that: 1) five surface stations installed within the surface projection of DI ensure localization thresholds ranging between $M_{L} 0.7$ and 0.8 within DI; 2) the installation of the borehole station allows to improve the detection threshold everywhere within DI, and down to $M_{L}=-0.4$ nearby the reservoir; and 3) localization thresholds obtained in the crustal volume included in DE, but not in DI, show values around $M_{L}=1.0$.
\end{abstract}

\section{Introduction}

The "Sant'Alberto" gas field is situated in the eastern part of the Po Plain (Italy), $35 \mathrm{~km}$ northeast of Bologna and $15 \mathrm{~km}$ southwest of Ferrara (Figure 1), within an area which has been already exploited for hydrocarbon production. The research projects for hydrocarbon exploitation began about sixty years ago. In 1956 for example, exploration activities carried out by AGIP/ENI company, allowed to identify and put into production the "San Pietro in Casale" gas field, in which 24 wells were drilled and, from 1959 to 1995 , a total production of about $500 \mathrm{MSm}^{3}$ was obtained from 14 exploitable wells through AGIP/ENI activity [PVO 2014]. At present, the above mentioned gas field lies within the area of the "San Vincenzo" exploration permit, owned by PoValley Energy (PVE), an oil \& gas E\&P company operating in the production and development of hydrocarbon assets in North of Italy [MiSE-DGS-UNMIG 2001]. The license, covers a $58.7 \mathrm{~km}^{2}$ area in the province of Bologna. In 2006, as part of this mining license, PVE presented to the Italian "Ministero dello Sviluppo Economico" the application for the hydrocarbon exploitation concession "Sant'Alberto" [MiSE-DGS-UNMIG 2006]. The involved area extends for $20 \mathrm{~km}^{2}$ and it is located in the municipalities of Galliera, Malalbergo and San Pietro in Casale [PVO 2014]. In 2011, PVE started a new exploration phase by acquiring a 31-line-km of $2 \mathrm{D}$ seismic survey, which confirmed the presence of a re-usable reservoir of about $50 \mathrm{MSm}^{3}$, deliverable in 12-15 years, from the exploration well named "Santa Maddalena 1 dir" (SM1d).

The development plan for the exploitation of the "Sant'Alberto" concession [PVO 2014], requires the evaluation of various aspects related to the impact of this facility on the territory. In particular, it is necessary to evaluate possible implication of the exploitation activities on induced seismicity. Because of the presence of important transportation routes (e.g. the BolognaPadova highway and the homonymous railway line) and of many production activities, the area of "Sant'Alberto" is affected by high levels of anthropogenic noise. This makes difficult to detect seismic signals eventually 

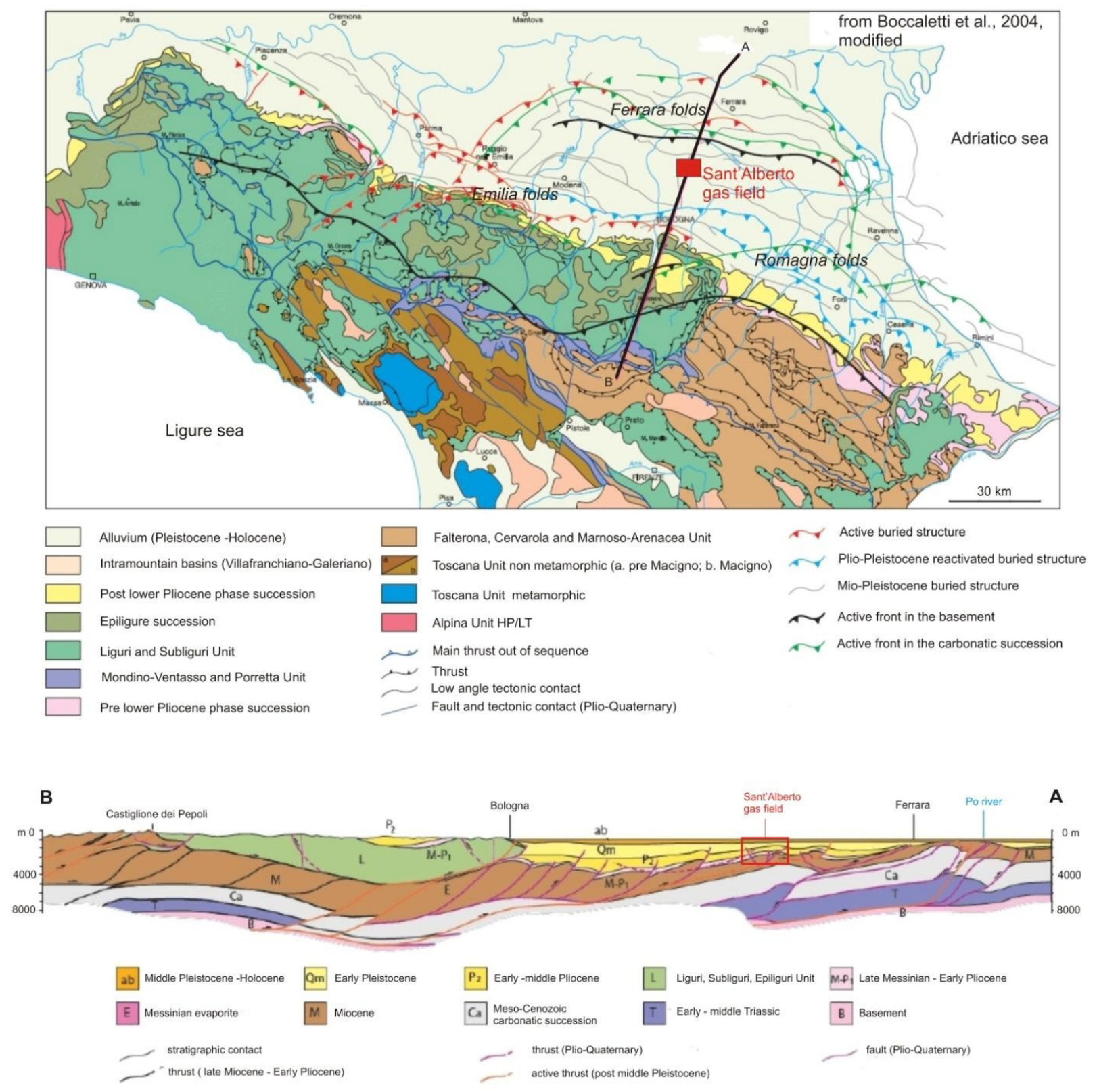

Figure 1. Top: scheme of the main tectonic - stratigraphic units in the areas of the Po Plain and northern Apennines. The black line marked as "A-B" corresponds to the trace of the section crossing the Sant'Alberto gas field (red rectangle). Bottom: reconstructions of the main structural-stratigraphic features of the section "A-B" modified from Boccaletti et al. [2004].

induced by exploitation activities. It is worth mentioning that the Italian National Seismic Network (RSN) shows a magnitude of completeness of about 2.0 in this region [Schorlemmer et al. 2010].

In the framework of the development plan for the start of production of SM1d, the INGV was commissioned to perform detailed investigation concerning the possible presence of active faults near the reservoir, and to realize a feasibility study of a network to monitor the local seismicity [PVO/ INGV-MI 2015]. In this paper, based on ground motion simulations, we present the results concerning the design of a microseismic monitoring network able to ensure adequate detection thresholds for possible man made earthquakes induced by exploitation activities of the reservoir. The network has been planned taking into account the guidelines for seismic monitoring issued by the Italian "Ministero per lo Sviluppo Economico DGS-UNMIG" [MiSE-DGS-UNMIG 2014], even if these criteria should be applied in case of expected production volumes greater than $200 \mathrm{MSm}^{3}$.

\section{Geological and seismotectonic setting}

The study area is located in the eastern part of the Po Plain, a foreland of two mountain ranges: the fold-and-thrust belt of the northern Apennines with 
convergence towards NNE and the south central Alps with convergence towards $S$ (Figure 1). This architecture is essentially due to the convergence between the European and African plates [Carminati et al. 2012]. The northern Apennine chain is formed by the superposition of different tectonic units, deformed and detached, partially or totally, from its own base. The shifting of the tectonic units, from very different paleogeographic domains, occurred through a long process started in the Oligocene. The current configuration of the northern Apennines is the result of intense tectonic phases, began in late Miocene (together with the opening of the Tyrrhenian basin), and important deformation of the eastern portion of the southern Alps.

Since 5 My at least, the Po Plain has undergone a continuous subsidence, which allowed the deposition of huge thick Plio - Quaternary terrigenous units of foredeep [Fantoni and Franciosi 2009, 2010] varying from a few hundred meters above the more superficial buried anticlines, to several thousand of meters (also exceeding $8000 \mathrm{~m}$ ) in coincidence of depocentre between the main fronts of thrusts. These formations, often debris flow deposits, refer to a deep foredeep environment (e.g., Bagnolo, Fusignano, Canopo, Porto Corsini, Porto Garibaldi, Carola formations). From the middle Pleistocene a continental deposition (Ravenna formation or Yellow Sands formation and Emiliano - Romagnolo supersynthem) takes place that testifies the rapid filling of the foredeep. [Ghielmi et al. 2010] stated that the Po - Adriatic foredeep was fueled mainly by materials eroded from the Alps and transported by paleo - rivers of Lombardy and Veneto as Adda, Mincio and Adige. Many stratigraphic units, coherently observed throughout the whole Po Plain basin, has been evidenced from the reconstruction of the sedimentary sequence (Figure 1). Starting from the bottom levels, these units are:

(1) a crustal base, the portion of the underlying Mesozoic sedimentary complexes of the Adriatic plate;

(2) a Mesozoic - Cenozoic sequence calcareous marl everywhere below the foredeep basin units. It is a set of formations deposited in a marine environment, of platform at first and then pelagic such as Calcare Massiccio formation, Rosso Ammonitico formation, Maiolica formation and Scaglia Toscana formation (Toscana Unit non metamorphic in Figure 1);

(3) a flyschoid group constituted by terrigenous sequences syn- and post - orogenic such as Gallare Marls, Marnoso-Arenacea and Cervarola formations (Falterona, Cervarola and Marnoso Arenacea Unit in Figure 1);
(4) a Messinian group consisting of sand, clay and sandstone with gypsum such as Gessoso Solfifera and Colombacci formations (pre lower Pliocene phase succession in Figure 1);

(5) a Pliocene group mainly characterized by clay, silt, and sand such as Clays of Santerno, Porto Corsini and Porto Garibaldi formations;

(6) a Quaternary sequence made up of alluvial deposits, clays, silts and sands such as Sands of Asti and Ravenna formation (Alluvium in Figure 1).

Historical and instrumental seismicity of the Po Plain is mainly concentrated along the foothills and the buried thrust fronts of the northern Apennines and southern Alps [Castello et al. 2006, Rovida et al. 2011, ISIDe Working Group INGV 2011]. In the Apennines, seismicity is not evenly distributed, but increases from west to east. Generally, the observed seismicity can be associated with the three complex fold systems that characterize the outer arcs of the northern Apennines, currently buried below the Pliocene-Quaternary sedimentary cover: the Monferrato Arc, the Emilia Arc, and the Ferrara-Romagna Arc. In particular, recent seismotectonic interpretations associate the seismic events recorded during the Emilia 2012 seismic sequence to the latter fold system [Pezzo et al. 2013, Chiarabba et al. 2014, Govoni et al. 2014, Carannante et al. 2015, Maesano et al. 2015].

From a structural point of view the study area lies in the "Ferrarese - Romagnola" ridge domain (Figure 1) constituted by a system of folds developed along an arched structure externally delimited by reverse faults and overthrusts that divide the folds from the Pedealpina monocline. The current structural setting of the ridge is the result of the Apennine compression occurred in the middle-upper Pliocene. The deformation is "fault - propagation folds" type with major detachments at the top of the carbonates. A feature common to many of the folds in the area is their marked asymmetry. Generally they have convergence towards the north with the northern side much more inclined and shorter than the southern one and interested by reverse faults; moreover, transverse displacements to the main axis of the folds, related to tectonic phase of extension, divide the structures in independent blocks. Specifically, the area of interest is part of an anticline that affects Miocene and Pliocene formations that were eroded at the top of the fold. The structures of the middle- upper Pliocene, also folded in anticline, are placed in transgression, while the upper Pleistocene sequences are represented by large sub horizontal levels of sand. 
Paying the attention to San Pietro in Casale reservoir, this structure can be defined as an anticline closed to the north by a reverse fault (frontal thrust ramp) oriented towards WNW - ENE and to the south from a back thrust. At east and west sides the trap is closed by minor faults perpendicular to the main one. The anticline involves the Miocene sequence and the overlying clay - sand deposits of the early Pliocene and presents at its top a surface of erosion which produced a partial removal of sands belonging to the Porto Corsini Formation constituting the reservoir rock. The sandy layers mainly belonging to groups PL1 (early Pliocene) and PL2 (middle - late Pliocene) and located at the top of Porto Corsini Formation and at the lower
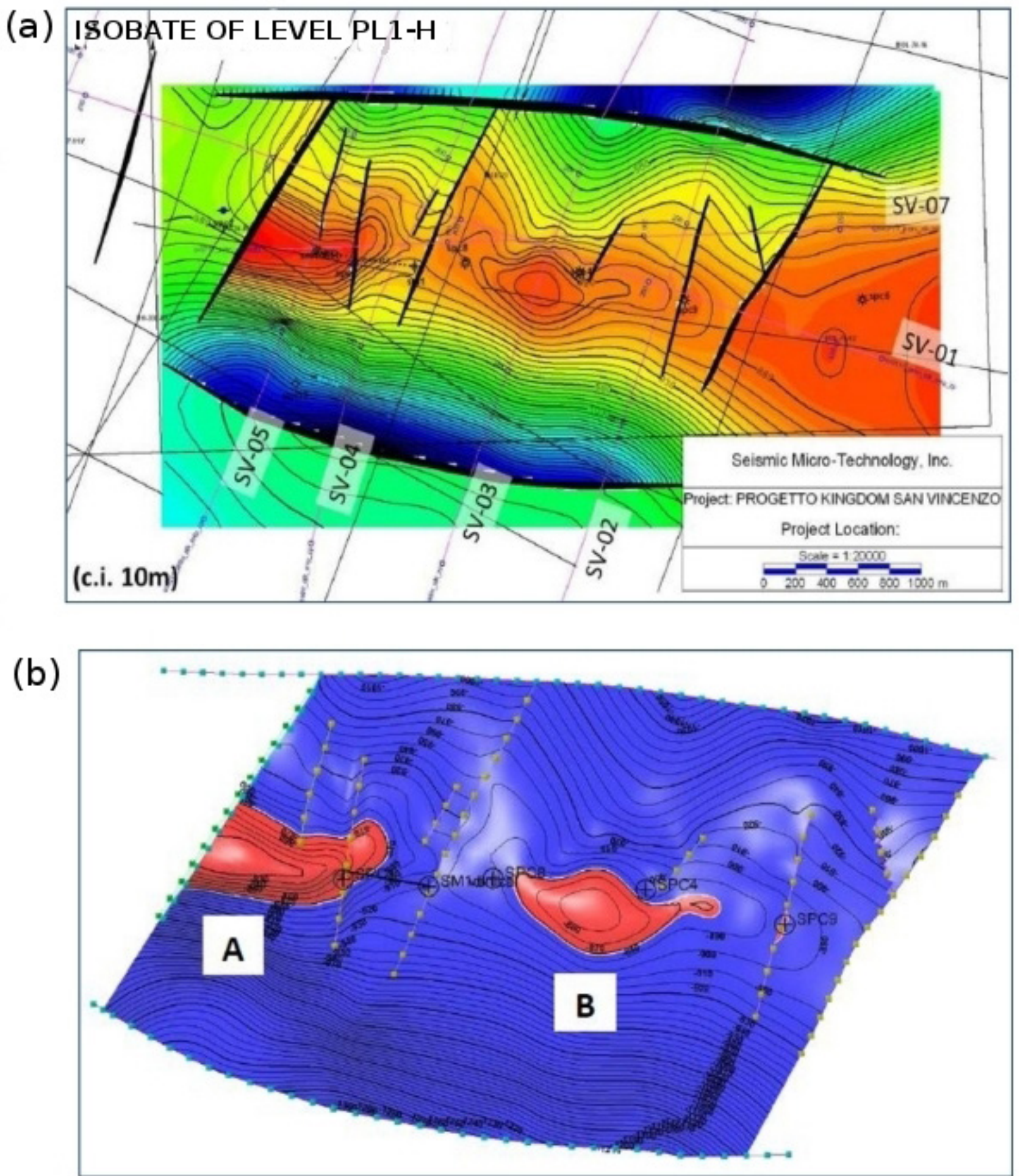

Figure 2. (a) Structural map of the early Pliocene PL1-H level, in which the geophysical lines obtained by PoValley Energy following the 2D seismic survey of 2011 are highlighted. (b) Structural culminations (A and B) of the PL1-H level, corresponding to the identified gas reservoirs. 
portion of the Porto Garibaldi Formation respectively, can operate as container for hydrocarbons that fill the pores within the rock. In the oilfield of interest, the main reservoir (PL1-H) is indeed represented by a structural trap in the sandy formation of Porto Corsini. This is also evidenced by the results obtained following the geophysical acquisition field, carried out in 2011 in the area where the well SM1d (Santa Maddalena 1 Dir) was drilled. The structural map of level PL1 - H (Figure 2a) shows two gas mineralized zones A and B separated by a saddle (Figure $2 \mathrm{~b}$ ): the area $\mathrm{A}$, located between 810 and $870 \mathrm{~m}$ depth which represents the western culmination on which insists the SM1d well and the area B, a culmination less marked and moved to the south than previous, with marginal remaining gas volumes.

\section{Monitoring area}

In order to increase the effectiveness in discriminating between possible man made earthquakes occurring near the gas reservoir and background natural seismicity of the area, we defined two different crustal volumes of earthquake detection: the inner domain of detection (hereafter DI) and the extended domain of detection (hereafter DE). The DI is defined as the crustal volume within which we expect to detect some type of induced seismicity. Therefore, within this volume, the planned monitoring network must reach the highest detection capability. The guidelines reported in MiSE-DGSUNMIG [2014], require to define DI by extending horizontally the area corresponding to the surface projection of the reservoir, and by considering the maximum depth of the reservoir as starting point in order to define the bottom of the monitored volume. In the case of oil and gas extraction activities without re-injection of fluids, the above mentioned guidelines require an extension of $3 \mathrm{~km}$ in any direction around the surface projection of the reservoir, as well as an increase of depth of $3 \mathrm{~km}$ for the definition of the bottom of DI, starting from the depth of the reservoir. The DE, defined as an extension of DI, is introduced in order to contextualize the monitoring performed by the microseismic network: in this volume, the planned network should improve the magnitude of completeness of the regional networks operating in the area.

As mentioned above, the structure of the "Sant'Alberto" gas reservoir is located on a blind ramp anticline, at depths ranging between 810 and $870 \mathrm{~m}$. The surface extension is about $0.4 \mathrm{~km}^{2}$ and the planned production activities for the reservoir exploitation

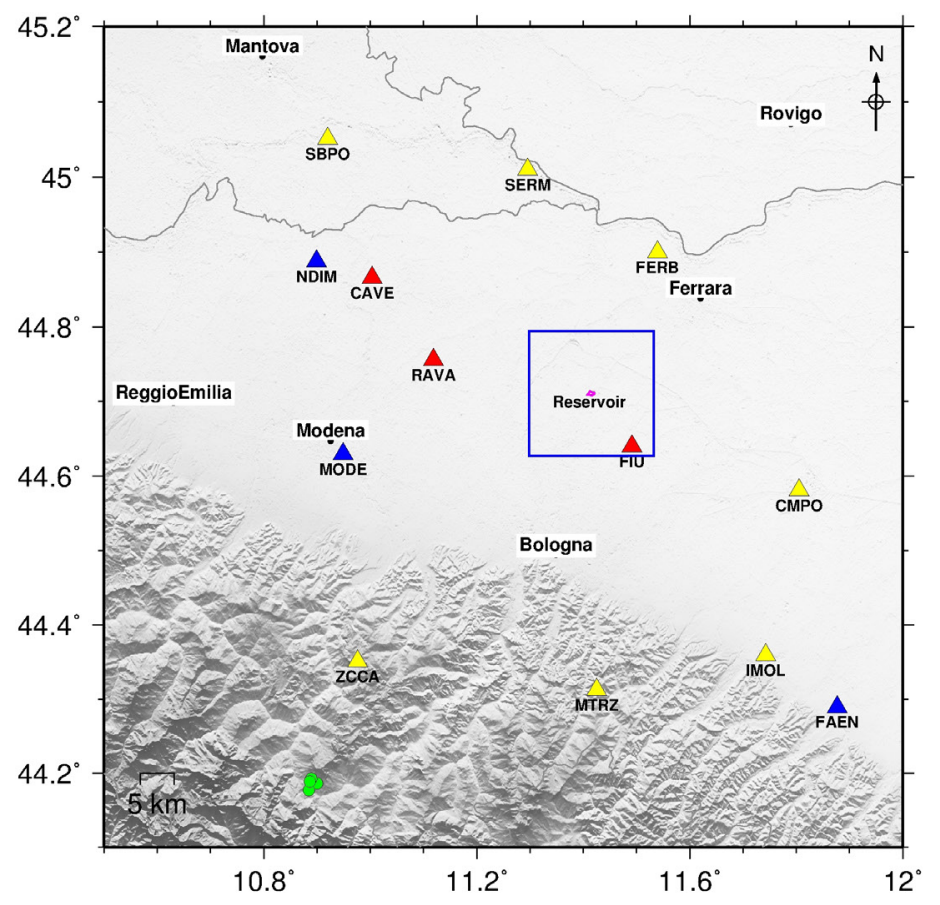

(a)

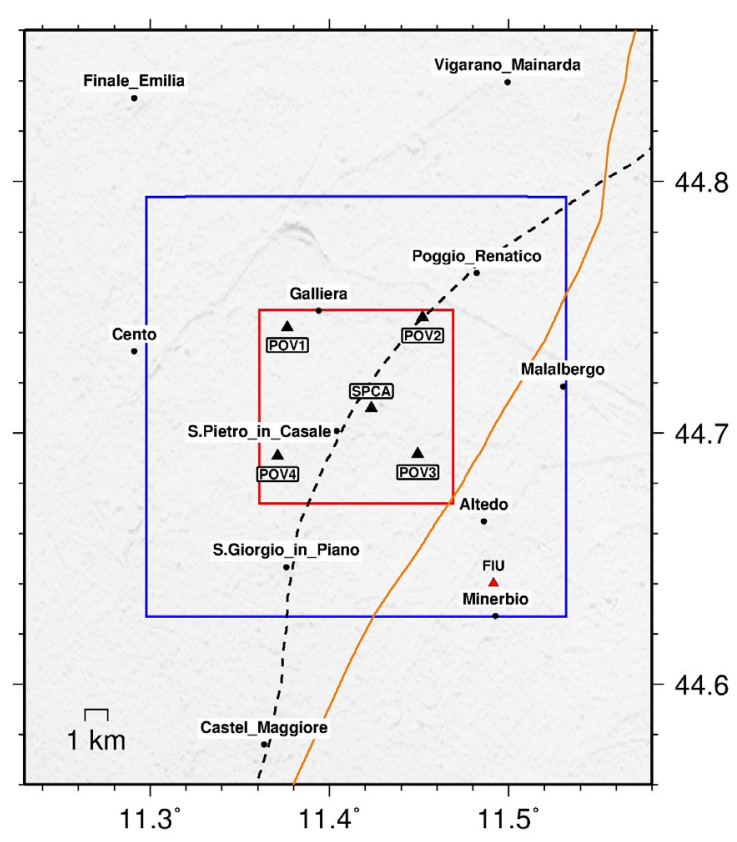

(b)

Figure 3. (a) Stations of the National Seismic Network (RSN) in an area of about $100 \times 100 \mathrm{~km}^{2}$ around the well SM1d, crossing the "Sant'Alberto" gas field (red triangles: velocimeters; blue triangles: accelerometers; yellow triangles: six channels stations). The green circles represent the events used for parameters calibration. The center of the area corresponds to the surface projection of the reservoir (magenta line). The blue box underlines the extended domain of detection (DE) (see text). (b) Inner and extended domains of detection (red and blue box, respectively) with some of the main sources of anthropogenic noise: highway (orange line) and railway line (black dotted line). The microseismic network composed of the 5 temporary stations installed in the area and the station FIU of RSN, are also shown. 
do not provide for re-injection of fluids [PVO 2014]. Considering the small extension of the "Sant'Alberto" reservoir, we defined $\mathrm{DE}$ by extending DI both horizontally and vertically, for a distance of $5 \mathrm{~km}$. We thus defined the surface projections of DI and DE as squared areas centered to the position of the SM1d well, with areas of $8.6 \times 8.6 \mathrm{~km}^{2}$ and $18.6 \times 18.6 \mathrm{~km}^{2}$, respectively (Figure 3). The bottoms of DI and DE were then fixed at 4.0 and $9.0 \mathrm{~km}$ depth, respectively.

The Italian National Seismic Network (RSN) counts on 12 stations within an area of $100 \times 100$ $\mathrm{km}^{2}$ centered to the "Sant'Alberto" reservoir (Figure 3a). The stations are characterized by a minimum inter-station distance of about $21 \mathrm{~km}$. As mentioned above, in this area the RSN shows a magnitude of completeness of about 2.0 and, as an example, a $\mathrm{M}_{\mathrm{L}} 1.5$ event occurring at $30 \mathrm{~km}$ depth has a $50 \%$ probability of detection [Schorlemmer et al. 2010]. The improvement in detection capabilities therefore requires an adjustment of the current network configuration, which includes the installation of a microseismic network in the area of the surface projection of $\mathrm{DE}$. In this work we evaluate the possibility to detect and locate seismic events with local magnitude of at least 0.5 and 1 , if occurring within DI and DE, respectively. For this purpose, a hypothetical network composed of five short period stations, with an average inter-station distance of 4-5 $\mathrm{km}$ has been considered (Figure $3 \mathrm{~b}$ ). The detection threshold is established by comparing simulated power spectra of earthquakes characterized by different values of magnitude and located within DE, with the power spectrum of the observed ambient noise. In order to minimize the influence of anthropic noise and to improve the network detection, we also consider the possibility to install at least one borehole sensor at $200 \mathrm{~m}$ depth.

\section{Evaluation of ambient seismic noise}

After defining the crustal volumes for seismicity monitoring, we proceed with the characterization of ambient seismic noise of the area. At the beginning, the seismic station SPCA, equipped with a Reftek-130 3-channels digitizer coupled to a Lennartz Le3d-5s seismometer, was installed in the inner area of the SM1d well, and recorded seismicity continuously for about three months, from June 13, 2015 to September 27, 2015. The recorded signals were transmitted in real time to the INGV data acquisition centre of Milan. The aim of installation is to evaluate the day-night variation of the average level of ambient noise. In the same period, the characterization of the seismic noise of the area has been carried out by extending the noise measures in four additional sites located within the surface projection of DI. On June 16, 2015, a measurement campaign, performed by four temporary stations with the same equipment of SPCA, that recorded simultaneous sequences of $1 \mathrm{~h}$ ambient noise,

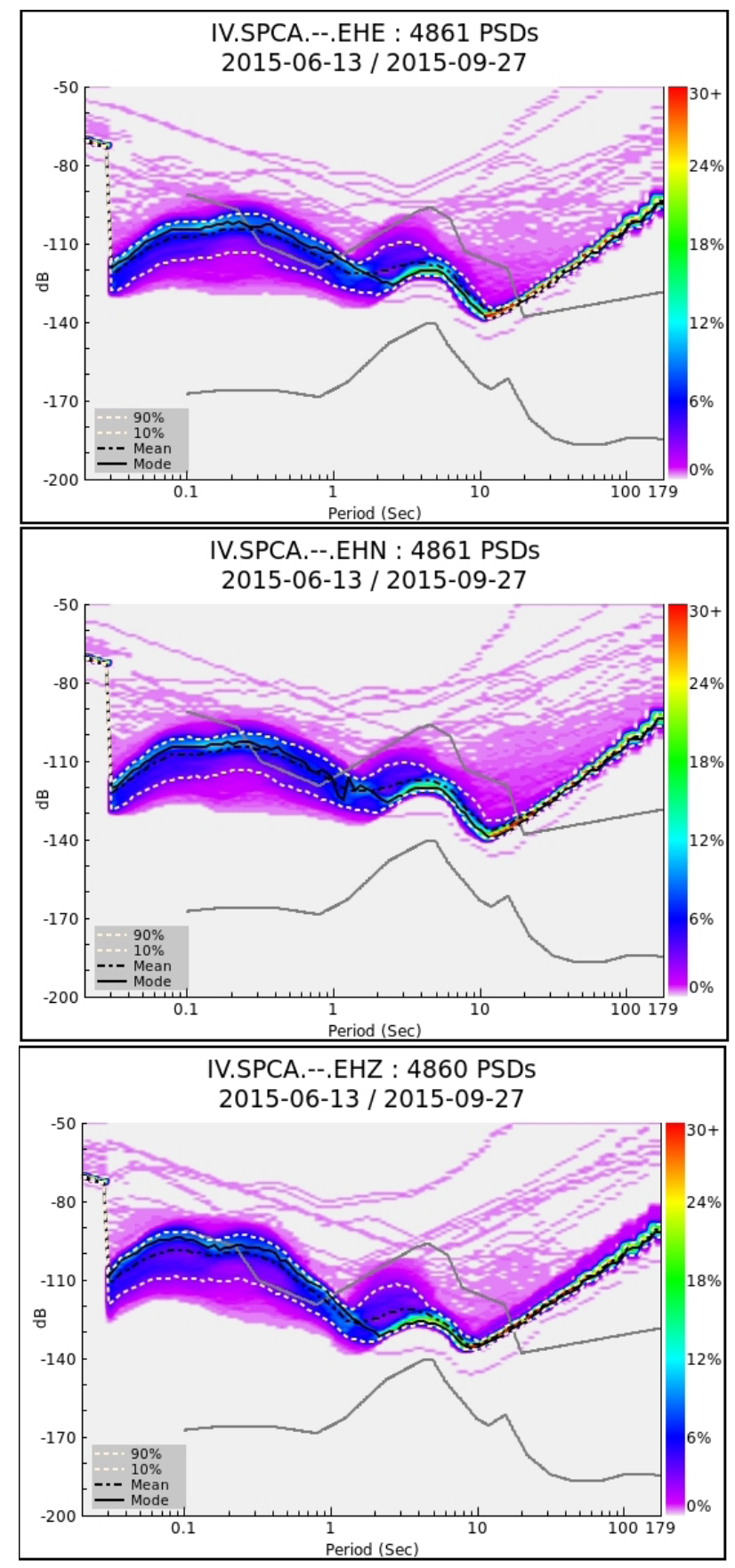

Figure 4. Probability density functions (PDF) of the acceleration power spectral density (PSD) of ambient seismic noise recorded at the SPCA site in the period June 13- September 27, 2015: overall distributions compared with the NHNM and NLNM curves of Peterson (1993) (grey lines) for each component of the ground motion. The colour scale represents the statistical frequency of the measured power spectral density, expressed in unit of $\mathrm{dB}$ referred to $1\left(\mathrm{~m} / \mathrm{s}^{2}\right)^{2} / \mathrm{Hz}$. 

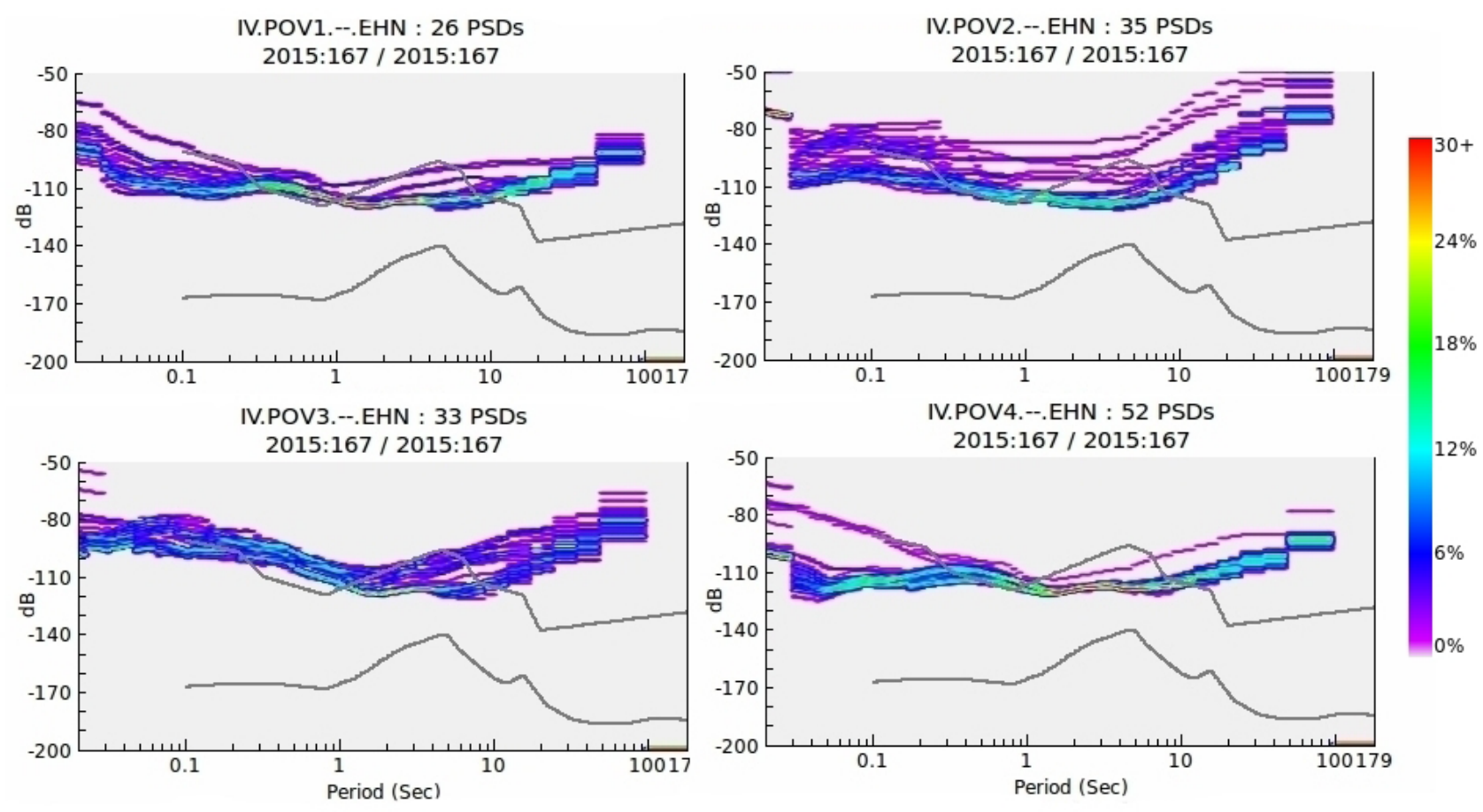

Figure 5. As in Figure 4, but for the ambient seismic noise recorded at the temporary stations POV1, POV2, POV3 and POV4 in 2 hours recording (NS component).

was carried out. Figure $3 \mathrm{~b}$ shows the position of the employed stations.

The analysis of ambient noise has been performed by computing the power spectral density (PSD) of the seismic signal recorded in the selected sites and comparing the corresponding probability density functions (PDF) with the standard reference curves NHNM (New High Noise Model) and NLNM (New Long Noise Model) obtained by Peterson [1993]. The PQLX software (http:earthquake.usgs.gov/research/ software/pqlx.php) was used to quantify the level of noise and its fluctuation. The software, based on the algorithm developed by McNamara and Buland [2004], estimates, in real time, the probability density function (PDF) of the power spectral density (PSD) for stationary random seismic data. The raw signal recorded at SPCA was processed using time windows of $3600 \mathrm{~s}$, with an overlap of $50 \%$, which are the basis for the evaluation of PDFs. The time window duration was chosen in order to assure an adequate number of samples for the PDF evaluation, considering that this station has been continuously recoding for about three months. For data recorded by the temporary stations, continuously recording for about 2 hours, we adopted time windows of $120 \mathrm{~s}$. Figures 4 and 5 show the results in terms of PDF of the acceleration PSD, computed with recordings of the station SPCA and of the four temporary stations employed in the seismic noise measurement campaign, respectively.
Figure 6 shows the corresponding spectrograms. It is worth mentioning that all measures were performed in summer time. Due to the features of the area, which essentially presents a farming vocation, we expect to observe in this period, higher levels of ambient seismic noise with respect to the winter time [Franceschina et al. 2015]. This should involve conservative estimates of the detection thresholds of the network.

By comparing the observed PDF of ambient seismic noise with the reference curves of Peterson [1993] (Figure 4), it appears that, for frequencies in a range between 1 and $3 \mathrm{~Hz}$, the mean levels of ambient noise at SPCA are about $12 \mathrm{~dB}$ above the NHNM curve. At higher frequencies, the noise decreases up to 10$20 \mathrm{~dB}$ under the curve. Moreover, it is worthwhile to highlight that also during the daily recording periods, the signal shows several transient disturbances (Figure 6a). All these facts suggest that this site is characterized by elevated average levels of anthropic noise and by a high frequency of transients. The results obtained with the temporary stations (Figure 5 and $6 \mathrm{~b}$ ) show that all of the considered sites are affected by elevated levels of ambient seismic noise. Indeed, power spectra distributions are generally comparable with the NHNM curve of Peterson [1993] in the range of frequencies 1-20 Hz. Differences up to 10-20 dB are observed in the mean ambient noise levels within the investigated area, depending on the position of the considered site with respect to the anthropic sources of disturbance. 


\section{Detection of seismic events}

The analysis of noise presented in the previous

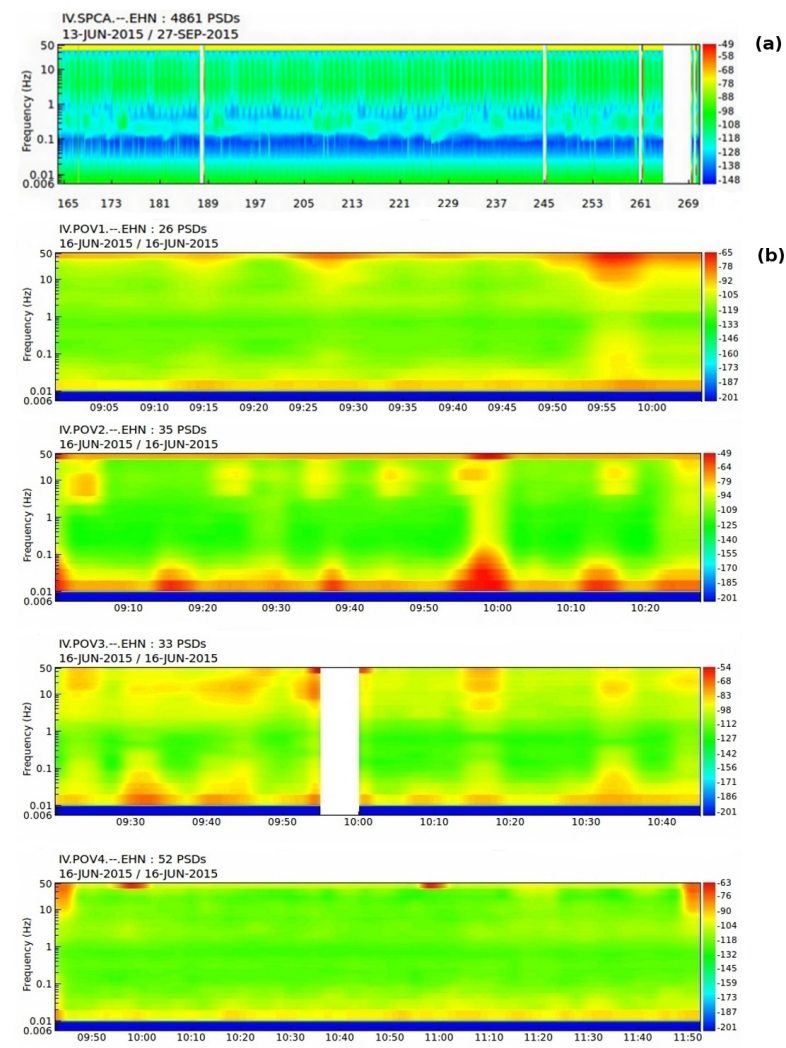

Figure 6. Spectrograms of the NS component of all stations. (a) SPCA: bottom labels indicate the Julian days. (b) Temporary stations: bottom labels indicate GMT hours. The colour scale represents the value of the power spectral density expressed in units of $\mathrm{dB}$ referred to $1\left(\mathrm{~m} / \mathrm{s}^{2}\right)^{2} / \mathrm{Hz}$.

section were employed to evaluate the sensibility of the seismic network to be designed, comparing the power spectrum of simulated earthquakes with the observed (or hypothesized) power spectrum of ambient seismic noise. Generally, earthquakes of lowto-moderate magnitude are simulated through point source models, and the Brune [1970, 1971] model is often employed to reproduce the amplitude Fourier spectrum of the $S$-waves, recorded at hypocentral distance $\mathrm{R}$. The source model neglects both finite fault effects and source directivity, and it is completely described by two parameters: seismic moment, $\mathrm{M}_{0}$, related to the earthquake magnitude, and corner frequency, $f_{c}$, related to the linear dimension of the source. The seismic wave attenuation can be simulated by multiplying the source spectrum by a distancedependent term, which takes into account of anelastic absorption; scattering and geometrical spreading. In this study we considered a $\mathrm{R}^{-1}$ dependence of geometrical spreading, a linear dependence on frequency of the quality factor, $Q(f)=Q_{o} f$, and a constant value of the high frequency decay parameter, $k$, of Anderson and Hough [1984]. As a consequence, the velocity amplitude Fourier spectrum of S-waves, recorded at hypocentral distance $R$ has been modelled by:

$$
V(f)=\frac{C \cdot M_{0}}{R} \cdot \frac{2 \pi f}{1+\left(\frac{f}{f_{c}}\right)^{2}} \cdot \exp \left(\frac{-\pi R}{\beta Q_{0}}\right) \cdot \exp (-k \pi f)
$$

where $\beta$ is the $S$ waves velocity, and the constant $C$ is given by: $C=F_{s} R_{\varnothing \omega} / 4 \pi \rho \beta^{3}$, with $F_{S}, R_{\emptyset \omega}$, and $\rho$ representing: the free surface factor, the radiation pattern factor, and the density of the medium, respectively. We adopted $\beta=2.2 \mathrm{~km} / \mathrm{s}$ and $\rho=2.4 \mathrm{~g} /$ $\mathrm{cm}^{3}$, according to the 1D model of Carannante et al. [2015], and assumed $R_{\emptyset \omega}=0.63$ for the RMS radiation pattern of $S$-waves, $F_{s}=2$ for surface stations and $F_{s}=1$ for borehole stations. For any $\mathrm{M}_{0}$ value, the corner frequency of the event was computed assuming a constant stress drop scaling with $\Delta \sigma=1 \mathrm{MPa}$ [Lay and Wallace 1995]. Moreover, we decided to express the final outcome of the work as detection thresholds of local magnitude, $\mathrm{M}_{\mathrm{L}}$. According to Hanks and Boore [1984], the seismic moment was related to $M_{L}$ using the bilinear relation:

$$
\begin{aligned}
& \log M_{0}=1.5 M_{L}+9.0 \quad\left(M_{L} \geq 3.0\right) \\
& \log M_{0}=1.0 M_{L}+10.5 \quad\left(M_{L}<3.0\right)
\end{aligned}
$$

As regards the $\mathrm{S}$-waves attenuation, recent studies performed in this region suggest a $\mathrm{Q}_{0}$ value of about 80 [Castro et al. 2013] and, from comparisons between simulated and recorded events we inferred an average value of $\mathrm{k}$ for the area of the reservoir. It is worth noting that the $\mathrm{k}$ value has considerable influence on the high frequency spectral decay. As a consequence, realistic evaluations of this parameter are necessary to ensure reliable estimates of the detection thresholds. It is well known that the $\mathrm{k}$ parameter is mainly related to site conditions, with values ranging between 10 $\mathrm{ms}$ (for rock sites) and $120 \mathrm{~ms}$ (for deep alluvial deposits), while generally, it shows a weak dependence on the epicentral distance. In this study, the k estimation was performed using data of a few seismic events (see Figure 3a) localized at about $73 \mathrm{~km}$ hypocentral distance from the reservoir area, and recorded from station SPCA. We simulated theoretical spectra through Equations (1) and (2). After performing several tests, an average value of $\mathrm{k}=80 \mathrm{~ms}$ was inferred from 

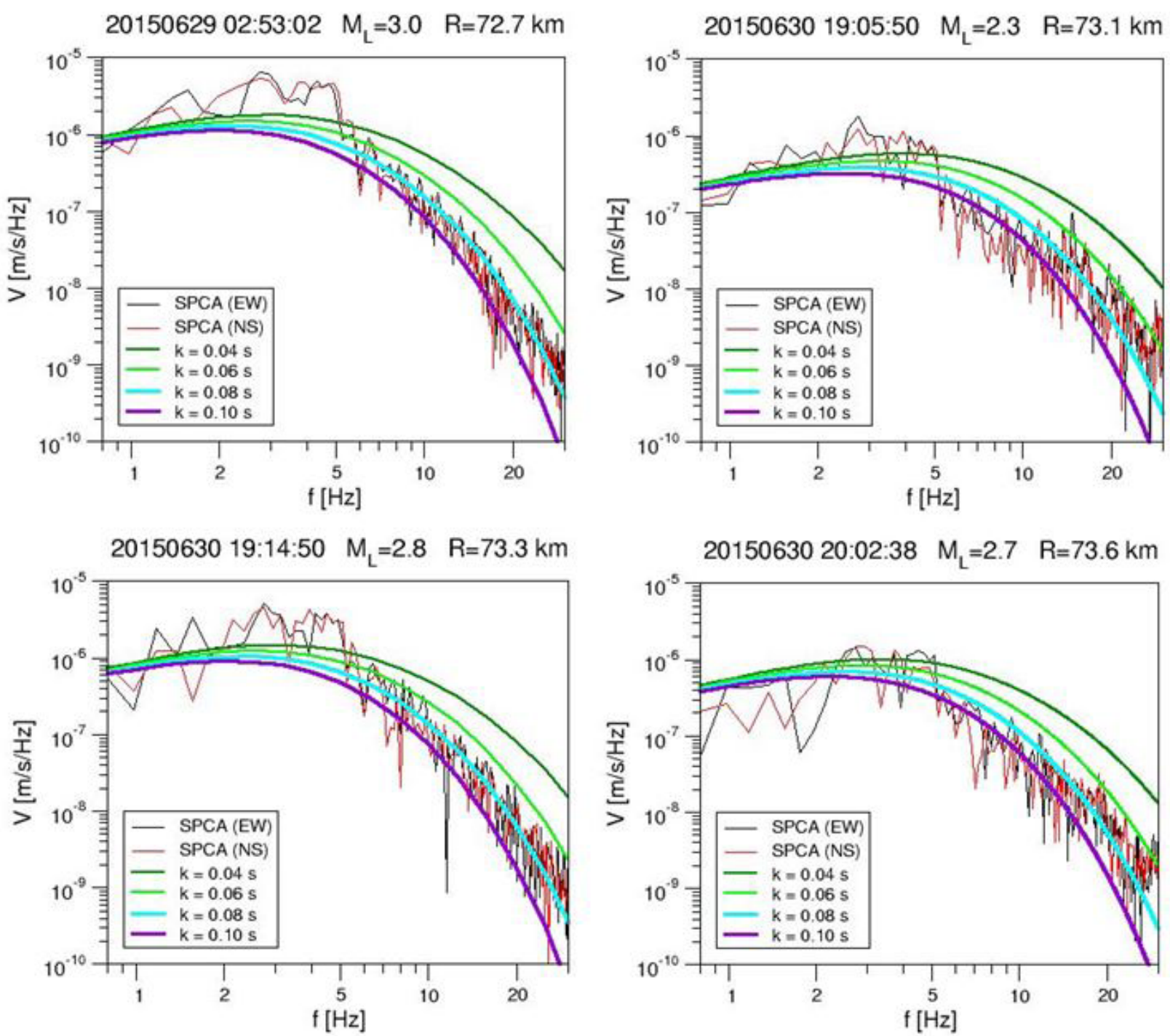

Figure 7. Comparison between simulated and observed amplitude Fourier spectra of the direct $S$-wave phase at the station SPCA for 4 earthquakes occurred at about $73 \mathrm{~km}$ distance from the reservoir. The horizontal components of the ground motion are compared with simulations obtained with different values of $\mathrm{k}$. Origin times and magnitudes of the events are indicated in the corresponding panels.

comparison between recorded and simulated S-wave amplitude Fourier spectra (see Figure 7).

\section{Microseismic network design}

After calibrating the parameters in Equation (1), a microseismic network composed of 5 stations with inter-station distances between 3 and $5 \mathrm{~km}$, installed in correspondence of the sites where noise measurements have been carried out, was hypothesized. We also hypothesized the possible installation of a borehole station at $200 \mathrm{~m}$ depth in correspondence to the SPCA site. For the borehole installation, we estimated a decreasing rate of $0.1 \mathrm{~dB} / \mathrm{m}$ of the mean noise level in the frequency band $1-20 \mathrm{~Hz}$, in accordance with ambient seismic noise estimates, performed at borehole stations installed in the Po Plain in sites characterized by similar geological settings [Franceschina et al. 2015]. In addition, for our simulations we also considered the station FIU of the National Seismic Network, located within the surface projection of DE at $9.4 \mathrm{~km}$ distance from SPCA. The adopted network configuration is shown in Figure $3 \mathrm{~b}$.

In order to establish the detection threshold of the network, we used point source simulations of earthquakes characterized by different values of magnitude and distance, comparing the power spectrum of the simulated earthquake (see Equation (1)) with the observed (or hypothesized) power spectrum of ambient seismic noise. Point source simulations were carried out for seismic sources placed in 625 equally-spaced points of 5 regular grids, located within DE at 1.0, 2.5, 4.0, 6.5 and $9.0 \mathrm{~km}$ depth, where the levels at 1.0, 4.0 and $9.0 \mathrm{~km}$ coincide with the depth of the "Sant'Alberto" gas field, the bottom of DI and the bottom of DE, respectively.

By adopting the above mentioned network 

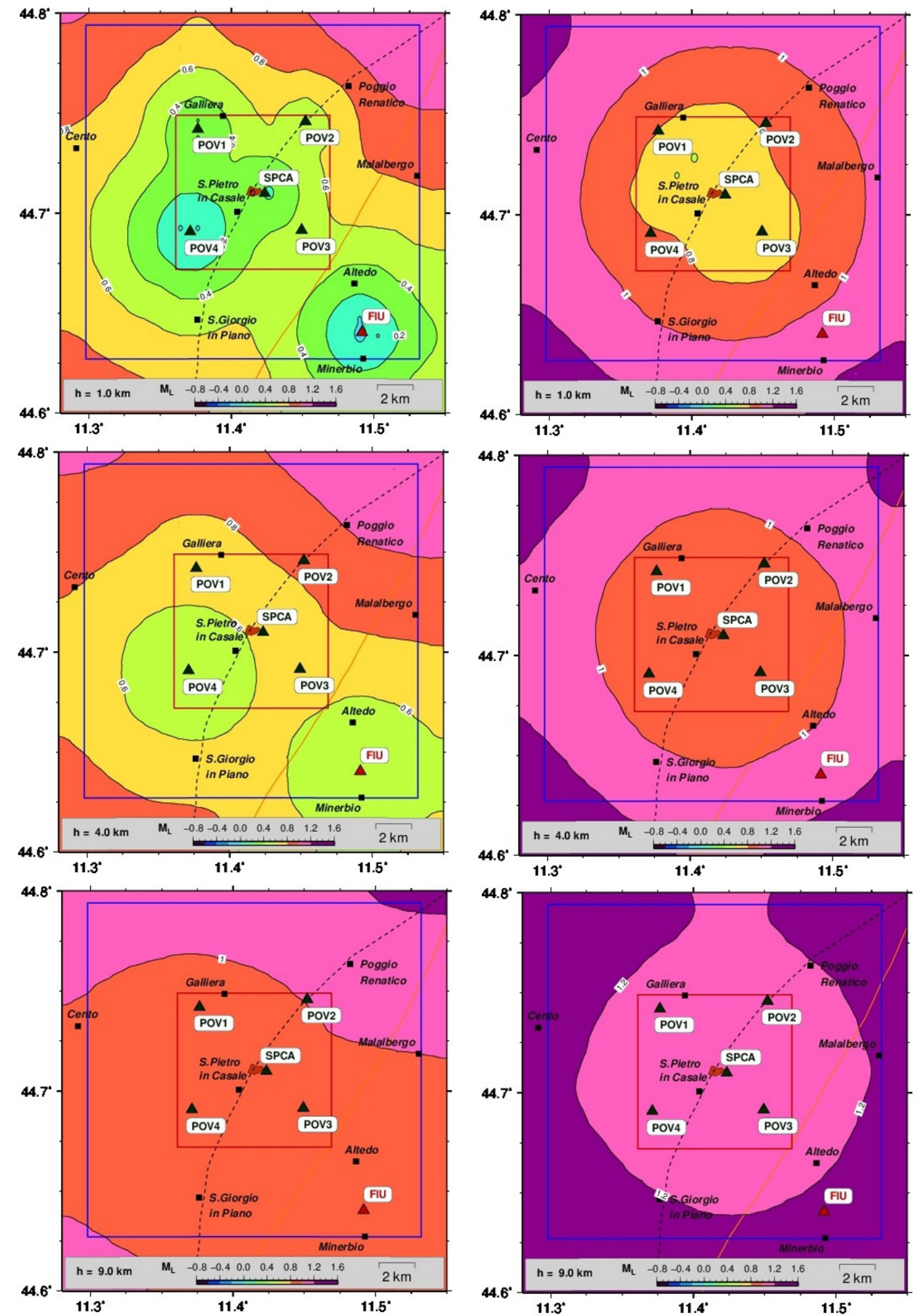

Figure 8. Detection and localization thresholds (left and right panels, respectively) expressed in units of magnitude $\mathrm{M}_{\mathrm{L}}$. For each station of the microseismic network the detection thresholds were computed by employing the observed levels of ambient seismic noise (case A, see text). From top to bottom: detection and localization thresholds for events located in the extended domain of detection at 1,0, 4.0 and $9.0 \mathrm{~km}$ depth, respectively. The localization threshold was calculated by imposing the detection of the earthquake by means of at least 3 stations of the network.

configuration, consisting of stations POV1, POV2, POV3, POV4, SPCA and FIU (see Figure 3b), three possible simulation scenarios, obtained with different combinations of the ambient noise levels, have been considered:

- Case A: all stations are characterized by the noise 

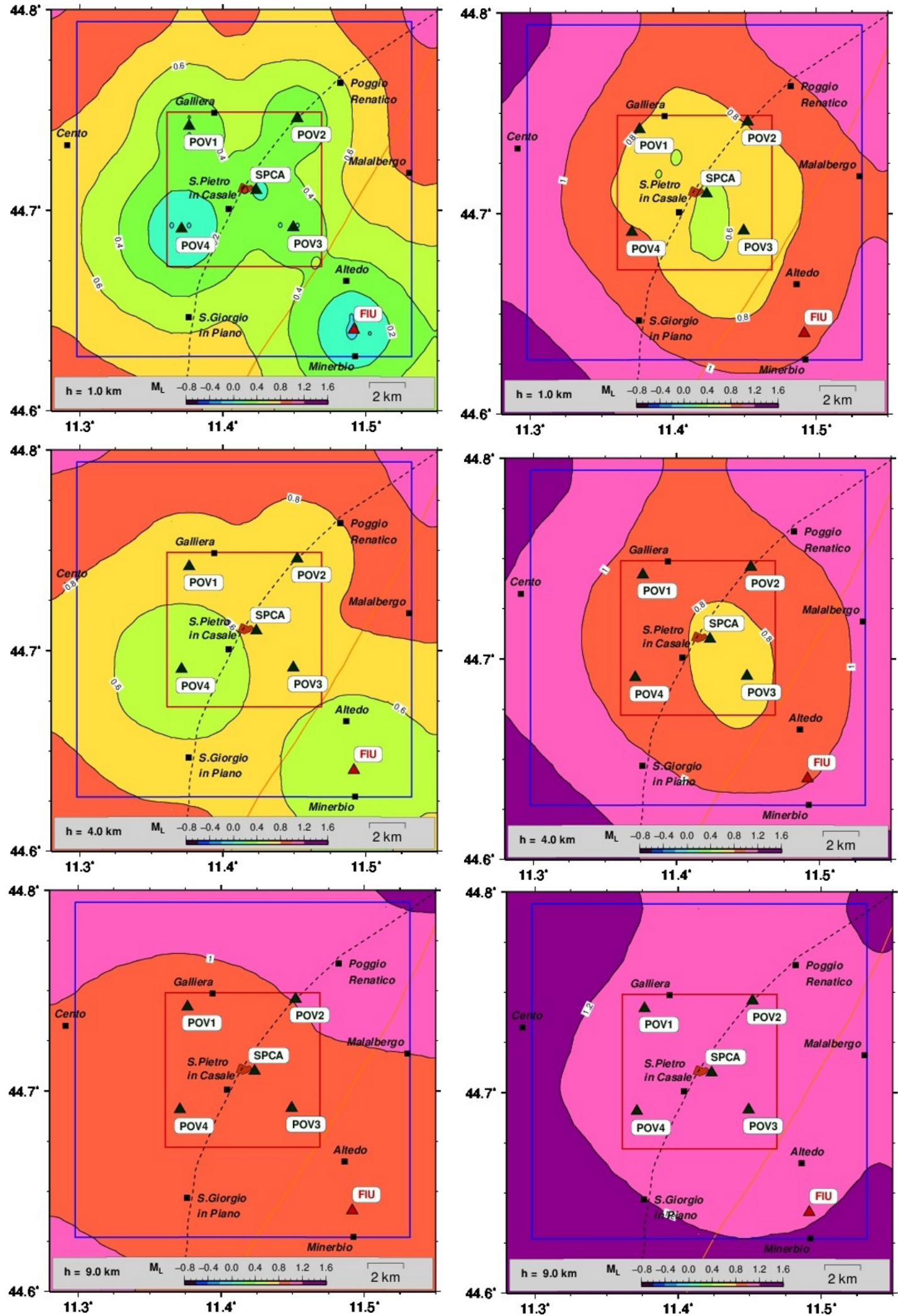

Figure 9. As in Figure 8, but with the use of altered levels of environmental noise. For the stations SPCA, FIU, POV1 and POV4, were employed the observed levels of ambient seismic noise, while for POV2 and POV3 were employed the noise levels of SPCA (case B, see text).

levels really observed at the respective sites;

- Case B: stations SPCA, FIU, POV1 and POV4, are characterized by the observed noise levels while the noise level observed at SPCA was arbitrarily assigned to POV2 and POV3;
- Case C: as in case B, with the exception of the SPCA site for which we hypothesized to move the sensor at $200 \mathrm{~m}$ depth. For this site we assumed a decreasing rate of the mean noise level with depth as above described. 

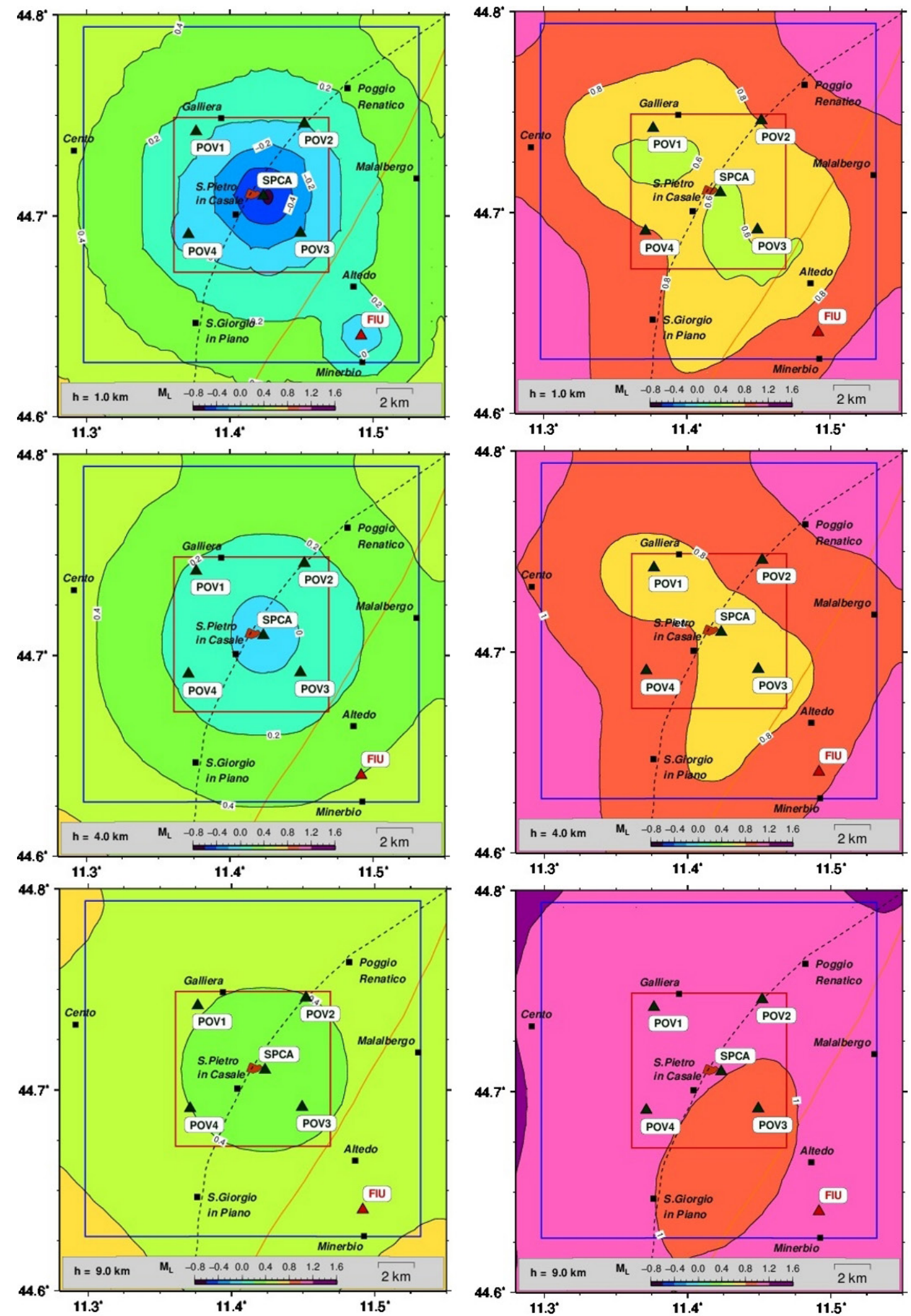

Figure 10. As in Figure 9, but with the use of a borehole station hypothetically installed in correspondence to SPCA at $200 \mathrm{~m}$ depth. In this case, for the noise level, it has assumed a decreasing rate of $0.1 \mathrm{~dB} / \mathrm{m}$ with depth (case $\mathrm{C}$, see text).

Cases $\mathrm{B}$ and $\mathrm{C}$ were simulated in order to design a seismic network of 5 stations with or without 1 borehole sensor installed at $200 \mathrm{~m}$ depth. Both cases were introduced with the aim to inquire the detection improvement obtained with an accurate selection of the monitoring sites and, eventually, with the installation of one of the sensors in a borehole. Consequently, the average noise levels for detection were assigned by considering the following points:

(1) In the frequency range $1-20 \mathrm{~Hz}$, the average 


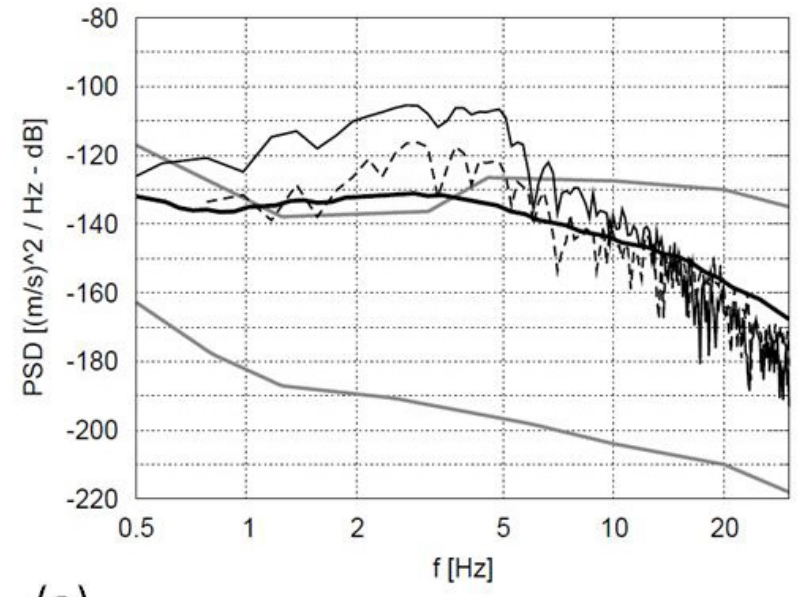

(a)

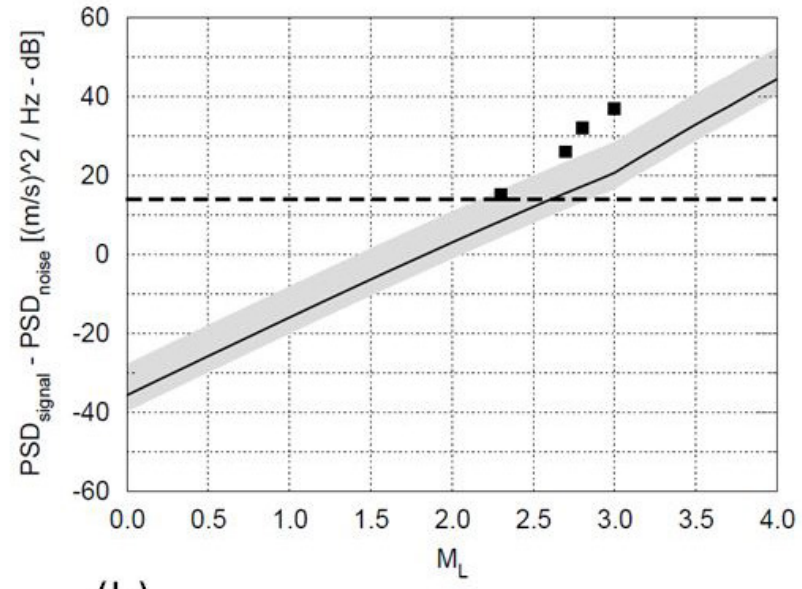

(b)

Figure 11. (a) Comparison between the velocity power spectra of the direct S-wave phase of two seismic events recorded by the station SPCA and the mean PSD of ambient seismic noise observed by the same station in the period June 13-September 27, 2015 (thick-solid black line). Thin-solid line: June 29, 2015 02:53:02 (GMT), $\mathrm{M}_{\mathrm{L}}=3.0$ (mainshock); thin-dashed line: June 30, 2015 19:05:50 (GMT), $\mathrm{M}_{\mathrm{L}}=2.3 . \mathrm{The}$ NHNM and NLNM curves of Peterson (1993) are also shown for comparison (thick-solid grey lines). (b) Signal-to-noise ratio, expressed in units of $\mathrm{dB}$ referred to $1(\mathrm{~m} / \mathrm{s})^{2} / \mathrm{Hz}$, as a function of $\mathrm{M}_{\mathrm{L}}$ magnitude for events localized at $73 \mathrm{~km}$ distance from SPCA. The solid black line and the shadow area represent the mean \pm 1 std of the simulated signal-to-noise ratios. Symbols represent the signal-to-noise ratios of four seismic events recorded on June 29-30, 2015. The dashed line represents the threshold of $14 \mathrm{~dB}$, considered in this work as detection limit.
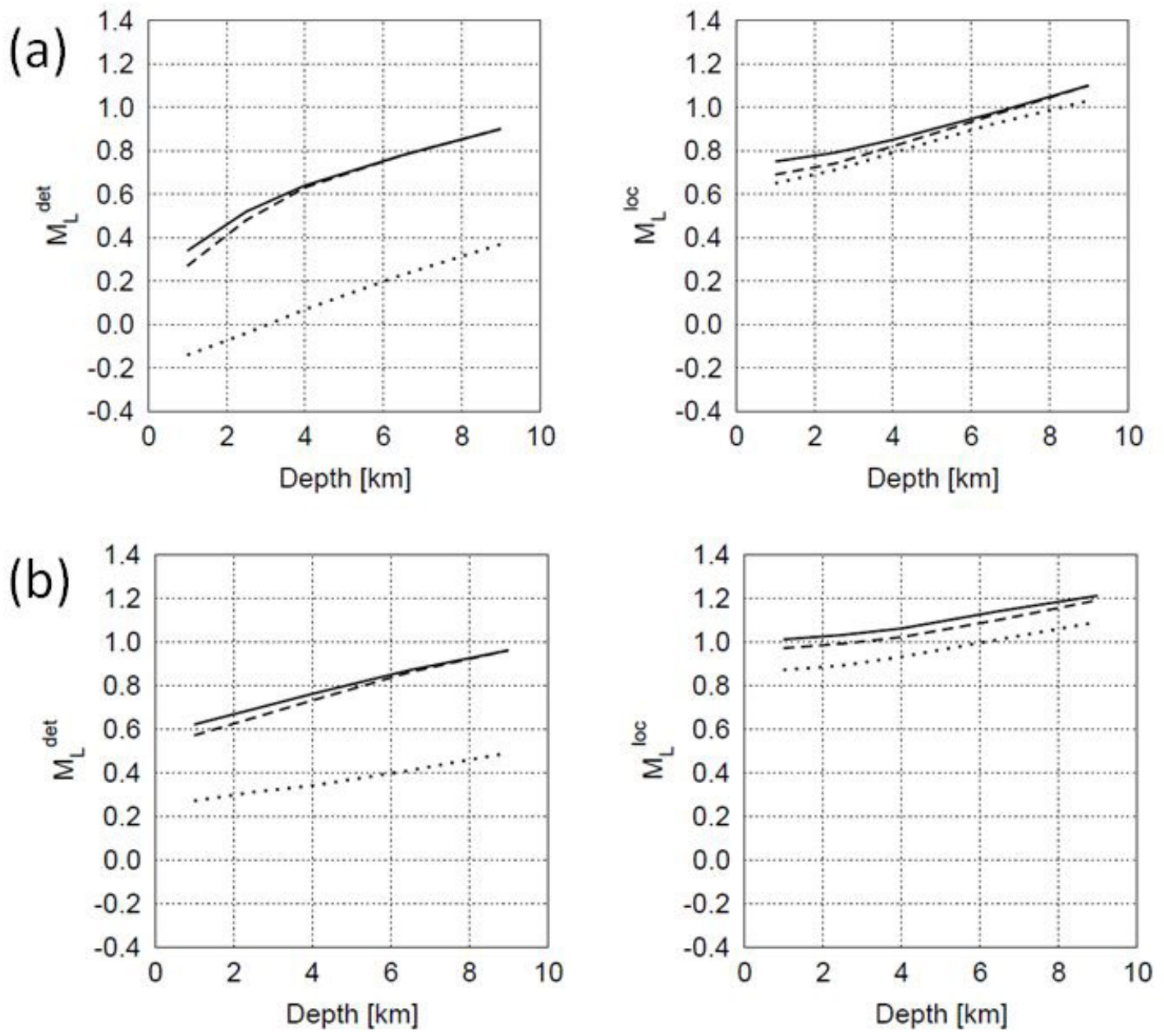

Figure 12. Mean detection and localization thresholds ( $\mathrm{M}_{\mathrm{L}}$ det and $\mathrm{M}_{\mathrm{L}}$ loc , respectively) as a function of depth. Solid, dashed and dotted lines represent the cases A, B and C, respectively (see text). (a) mean values over a surface corresponding to the surface projection of DI; (b) mean values over a surface corresponding to the surface projection of DE-DI. 
level of ambient seismic noise was accurately measured at the SPCA site during the 3 month period of installation of the temporary station (see Figure 4);

(2) 2 hours measurements carried out at POV1 site confirmed this level, while measures carried out at POV4 show that this site seems to be roughly characterized by a $10 \mathrm{~dB}$ lower level of noise (see Figure 5);

(3) The same measure carried out at POV2 and POV3 shows higher average levels, but also higher variability of seismic noise with respect to POV1 and POV4, probably reducible through a more accurate selection of the respective recording sites (see Figure 5).

For each source-station couple, the power spectrum of a seismic signal of $4 \mathrm{~s}$ duration, generated by earthquakes with locale magnitudes ranging between -1.0 and 3.0, has been computed, and then compared with the corresponding power spectrum of the observed (or hypothesized) noise. We considered a seismic event as detectable if the signal to noise ratio is greater than 5 (namely $\sim 14 \mathrm{~dB}$ ) in correspondence to the corner frequency of the source and we defined the detection threshold $\left(\mathrm{M}_{\mathrm{L}}{ }^{\text {det }}\right)$ as the minimum magnitude at which an earthquake can be recorded by at least one station. Afterwards, in this work we classified a seismic event as localizable when detected by at least 3 stations of the network, and we defined the localization threshold $\left(\mathrm{M}_{\mathrm{L}}{ }^{\mathrm{loc}}\right)$ as the minimum magnitude at which an earthquake can be localized. Detection and localization thresholds obtained in the cases A, B and C are shown in Figures 8, 9 and 10, respectively. The results are shown for 1.0, 4.0 and 9.0 $\mathrm{km}$ depth.

Depending on the detection of a certain number of stations, localization maps are generally characterized by a more homogeneous distribution of the magnitude values with respect to detection maps. Localization maps also show higher mean values and narrower distributions of magnitude with respect to detection maps. At the depth of the reservoir, as an example, in an area corresponding to the surface projection of DI the ranges of $\mathrm{M}_{\mathrm{L}}$ det are $[0.0-0.6] ;[0.0-0.4]$ and $[-0.6-0.0]$ in the cases $\mathrm{A}, \mathrm{B}$ and $\mathrm{C}$, respectively. Corresponding $\mathrm{M}_{\mathrm{L}}^{\text {loc }}$ are confined in the ranges $[0.6-0.8] ;[0.4-0.8]$ and [0.4 -0.8$]$, respectively. Moving from case $B$ to case $\mathrm{C}$, the area with $0.4<\mathrm{M}_{\mathrm{L}}^{\text {loc }}<0.6$ increases from about $15 \%$ to $30 \%$ of the surface projection of DI. At the bottom of DI, in an area corresponding to the surface projection of DI the ranges of $\mathrm{M}_{\mathrm{L}}{ }^{\text {loc }}$ are $[0.8$ - 1.0]; [0.7 - 1.0] and [0.7 - 1.0] in the cases A, B and
C, respectively, with the area characterized by $0.7<$ $\mathrm{M}_{\mathrm{L}}{ }^{\text {loc }}<0.8$ that increases from about $30 \%$ to $60 \%$ of the surface projection of DI, moving from case B to case $\mathrm{C}$. Within the crustal volume included in DE but not in DI, both $\mathrm{M}_{\mathrm{L}}{ }^{\text {det }}$ and $\mathrm{M}_{\mathrm{L}}{ }^{\text {loc }}$ are much higher. In particular, at the bottom of $\mathrm{DE}$, the ranges of $\mathrm{M}_{\mathrm{L}}$ loc are [1.1 - 1.4]; [1.1 - 1.4] and [0.9 - 1.2] in the cases A, B and $\mathrm{C}$, respectively. Moreover, it is worth noting that in this volume, earthquake locations are affected by large location errors due to the inadequate network configuration [Husen and Hardebeck 2010].

\section{Discussion}

The procedure employed in this work to assess the detection limits of the network, has been verified thanks to the recording of a few seismic events occurred in the northern Apennines. According to the Italian Seismic Bulletin (ISIDe 2016), on June 29, 2016, a $\mathrm{M}_{\mathrm{L}} 3.0$ earthquake, followed by some smaller events, occurred at about $73 \mathrm{~km}$ distance from SPCA. We compared the power spectra of these events, obtained from velocity records of SPCA, with the mean level of the ambient seismic noise calculated over the whole installation period of the station. Figure 11a shows the results as regard to the NS components recorded during the mainshock and a following $M_{L} 2.3$ event, respectively. In the frequency band $1-10 \mathrm{~Hz}$, the power spectrum of the mainshock, computed on a time window corresponding to the direct $\mathrm{S}$-wave phase recording, is clearly above the mean noise level of the station. Instead, the $M_{L} 2.3$ event, shows a power spectrum slightly higher than the mean noise level between 2 and $6 \mathrm{~Hz}$. In order to quantify the results, we computed the theoretical detection thresholds of SPCA for events located at 73 $\mathrm{km}$ distance and compared the simulations with the signal-to-noise ratios observed for the events of the sequence. Figure $11 \mathrm{~b}$ shows the signal-to noise ratio (in terms of power spectral density difference) for simulated earthquakes with $\mathrm{M}_{\mathrm{L}}$ magnitude ranging between 0.0 and 4.0 and for a few $M_{L} \geq 2.0$ events. All these earthquakes show values of the signal-to-noise ratio above the threshold of $14 \mathrm{~dB}$, considered in this work as detection limit. Moreover, it is apparent from the figure that signal-to-noise ratios of the recorded events are higher than what we would expect in the case of average conditions of ambient seismic noise. Indeed, the mainshock occurred at 02:53 GMT and the other three events occurred between 19:00 and 20:00 GMT, when the observed noise is up to 2 standard deviations under the mean. Figure $11 \mathrm{~b}$ thus 
evidences that the simulated signal-to-noise ratio is generally realistic and confirms the reliability of the procedure adopted in this work to evaluate the detection limits of the network.

The results shown in Figures 8, 9 and 10 are synthesized in Figure 12, where mean detection and localization thresholds computed for the surface projection of DI, $S_{D I}$, and for the surface projection of DE not included in $\mathrm{DI}_{\mathrm{I}}, \mathrm{S}_{\mathrm{DE}-\mathrm{DI}}$, are drawn as a function of depth. Improvements in both detection and location thresholds obtained in the transition from case A to B (solid and dashed lines, respectively) are related to the possibility of exploiting eventual low-noise site on the surface. Only a small increase ( $<0.1$ unit magnitude) of $\mathrm{M}_{\mathrm{L}}$ det and $\mathrm{M}_{\mathrm{L}}$ loc is observed in both $S_{\mathrm{DI}}$ and $S_{\mathrm{DE}-\mathrm{DI}}$. However it is worth noting that the computed detection thresholds refer to the average noise level, so that, seismic installations in low-noise sites are however useful in order to decrease the frequency of transient signals of anthropic origin in the recorded time series.

In order to obtain a significant improvement of $\mathrm{M}_{\mathrm{L}}{ }^{\text {det }}$ it is necessary to install at least one borehole station, indicatively at depths of at least $200 \mathrm{~m}$; in this case, an average improvement of 0.5 and 0.3 unit magnitude in $\mathrm{S}_{\mathrm{DI}}$ and $\mathrm{S}_{\mathrm{DE}-\mathrm{DI}}$, respectively is observed at all depths (see Figure 12). As regard to $\mathrm{M}_{\mathrm{L}}$ loc , it can be observed a general improvement of only 0.1 unit magnitude, due to the different detection thresholds of surface and borehole stations. By applying the minimal requirement that location can be performed only when the event has been detected by at least 3 stations of the network, a significant improvement of $\mathrm{M}_{\mathrm{L}}{ }^{\text {loc }}$ can be obtained only through the installation of at least 3 borehole stations. However, it is worth mentioning that the network configuration of case $\mathrm{C}$ ensures a general improvement of the detection threshold up to $4 \mathrm{~km}$ depth. In particular, the borehole station installed in correspondence of SPCA, is capable to detect $\mathrm{M}_{\mathrm{L}}-0.4$ events, located at the depth of the reservoir. A certain number of these earthquakes could be however recognized in the recordings of the surface stations, even if in DI, $\mathrm{M}_{\mathrm{L}}{ }^{\text {loc }}$ ranges from 0.6 to 0.8 .

It is evident from Figure 10, that also in the most favourable case, detection and localization thresholds obtained in DE are particularly elevated, with $\mathrm{M}_{\mathrm{L}}{ }^{\text {loc }}$ values greater than 1.0 in the deeper part of DE. Moreover, it is important to highlight that in this part of the extended domain the localization of seismic events would be affected by remarkable errors due to the inadequate stations distribution [Husen and Hardebeck 2010]. For a more accurate and homogeneous localization of seismic events occurring within the whole extended domain, it would be necessary to install at least three stations, properly distributed around the surface projection of the reservoir, at the same distance of FIU.

\section{Conclusions}

The following results can be highlighted:

(1) The area of the "Sant'Alberto" gas field is characterized by high levels of anthropogenic noise with PSD distributions of ambient seismic noise, generally comparable with the NHNM curve of Peterson [1993] in the range of frequencies: 1-20 Hz. Differences up to $10-20 \mathrm{~dB}$ are observed in the mean ambient noise levels within the investigated area, depending on the position of the considered site with respect to the anthropic sources of disturbance.

(2) The recording of a few seismic events, localized at about $73 \mathrm{~km}$ distance from the investigated area, confirms that detection and localization thresholds can be realistically evaluated by comparing synthetic power spectra of point sources located in different positions within the crustal volume surrounding the reservoir, with the observed mean levels of the PSD of ambient seismic noise.

(3) The effectiveness in discriminating between possible man made earthquakes occurring near the gas reservoir and background natural seismicity of the area, can be improved by defining two different crustal volumes of earthquake detection: the inner domain of detection, DI $\left(8.6 \times 8.6 \times 4.0 \mathrm{~km}^{3}\right)$ and the extended domain of detection, DE (18.6 x18.6 x 9.0 $\mathrm{km}^{3}$ ), both centered on the position of the reservoir (located at about $1.0 \mathrm{~km}$ depth).

(4) A network configuration consisting of 5 surface stations installed within the surface projection of DI ensures localization thresholds, $\mathrm{M}_{\mathrm{L}}^{\text {loc }}$, ranging between 0.7 and 0.8 within DI.

(5) The installation of a borehole station at 200 $\mathrm{m}$ depth in correspondence to the position of the reservoir, allows to improve the detection threshold, $M_{L}^{\text {det }}$, everywhere within DI, and down to $M_{L}=-0.4$ nearby the reservoir.

(6) Localization thresholds obtained in the crustal volume included in DE, but not in DI, generally show values around $\mathrm{M}_{\mathrm{L}}=1.0$ but, especially in the outermost parts of the extended domain, the localization of seismic events would be affected by remarkable errors due to the inadequate stations distribution. 
Acknowledgements. This research has benefited from funding provided by "Po Valley Energy Limited (PVE)". The study was carried out thanks to information made available by PVE. We thank PVE for having allowed the installation of the temporary station SPCA in an owned area and supported the necessary maintenance operations. We thank the AG Editor, Francesca Bianco, and the anonymous reviewer for their constructive comments, which helped to improve the final version of the manuscript.

\section{References}

Anderson, J. G. and S. E. Hough (1984). A model for the shape of the Fourier amplitude spectrum of acceleration at high frequencies, Bull. Seism. Soc. Am., 74, 1969-1993.

Boccaletti, M., M. Bonini, G. Corti, P. Gasperini., L. Martelli, L. Piccardi, C. Tanini and G. Vannucci (2004). Carta simotettonica della regione Emilia Romagna, 1:250.000 e note illustrative, SELCA Editore, Firenze.

Brune, J. N. (1970). Tectonic stress and the spectra of seismic shear waves from earthquakes, J. Geophysical Res., 75, 4997-5009.

Brune, J. N. (1971). Correction, J. Geophysical Res., 76, 5002.

Carannante, S., A. Argnani., M. Massa, E. D'Alema, S. Lovati, M. Moretti, M. Cattaneo and P. Augliera (2015). The May 20 (MW 6.1) and 29 (MW 6.0), 2012, Emilia (Po Plain, northern Italy) earthquakes: New seismotectonic implications from subsurface geology and high-quality hypocenter location, Tectonophysics, doi:10.1016/j.tecto.2015.05.015.

Carminati, E., M. Lustrino and C. Doglioni (2012). Geodynamic evolution of the central and western Mediterranean: Tectonics vs. igneous petrology constraints, Tectonophysics, 579, 173-192.

Castello, B., G. Selvaggi, C. Chiarabba and A. Amato (2006). CSI Catalogo della sismicità italiana 1981-2002, v. 1.1. INGV-CNT, Roma, http:/ / www.ingv.it/CSI/ .

Chiarabba, C., P. De Gori, L. Improta, F.P. Lucente, M. Moretti, A. Govoni, M. Di Bona, L. Margheriti, A. Marchetti and A. Nardi (2014). Frontal compression along the Apennines thrust system: The Emilia 2012 example from seismicity to crustal structure, Journal of Geodynamics, 82, 98-109.

Castro, R., F. Pacor, R. Puglia, G. Ameri, J. Letort, M. Massa and L. Luzi (2013). The 2012 May 20 and 29, Emilia earthquakes (Northern Italy) and the main aftershocks : S-wave attenuation, acceleration source functions and site effects, Geophys. J. Int., 195, 1, 597611, doi: 10.1093 / gji/ggt245.

Fantoni, R. and R. Franciosi (2009). Mesozoic extension and Cenozoic compression in Po Plain and Adriatic foreland, Rendiconti online Società Geologica Italiana, 9, 28-31.
Fantoni, R. and R. Franciosi (2010). Tectonosedimentary setting of the Po Plain and Adriatic foreland, Rendiconti Lincei, 21(1), 197-209.

Franceschina, G., P. Augliera, S. Lovati and M. Massa (2015). Surface seismic monitoring of a natural gas storage reservoir in the Po Plain (northern Italy), Bollettino di Geofisica Teorica e Applicata, DOI 10.4430/bgta0165, Vol. 56, n. 4, pp. 489-504.

Ghielmi, M., M. Minervini, C. Nini, S. Rogledi, M. Rossi and A. Vignolo (2010). Sedimentary and Tectonic Evolution in the Eastern PoPlain and Northern Adriatic Sea Area from Messinian to Middle Pleistocene (Italy), in F.P. Sassi, G. Dal Piaz, and C. Doglioni, (eds.), Nature and Geodynamics of the Northern Adriatic Lithostere: Rend. Fis. Acc. Lincei, v. 21/1, p. 131-166.

Govoni, A., A. Marchetti, P. De Gori, M. Di Bona, F.P. Lucente, L. Improta, C. Chiarabba, A. Nardi, L. Margheriti, N. Piana Agostinetti, R. Di Giovambattista, D. Latorre, M. Anselmi, M. G. Ciaccio, M. Moretti, C. Castellano and D. Piccinini (2014). The 2012 Emilia seismic sequence (Northern Italy): imaging the thrust fault system by accurate aftershocks location, Tectonophysics, http: / / dx.doi.org/10.1016/j.tecto.2014.02.013.

Hanks, T. C. and D. M. Boore (1984). Momentmagnitude relations in theory and practice. J. Geophysical Res., 89, 6229-6235.

Husen, S. and J. L. Hardebeck (2010). Earthquake location accuracy, Community Online Resource for Statistical Seismicity Analysis, doi: 10.5078/ corrsa-55815573, http: / www.corssa.org.

ISIDe Working Group INGV (2016). Italian Seismological Instrumental and parametric database (version 1.0), doi: 10.13127 / ISIDe, http: / / iside.rm.it.

Lay, T. and T. C. Wallace (1995). Modern global seismology, International Geophysics Series, 58, Academic Press, San Diego (USA), 521 pp.

Maesano, F. E., C. D'Ambrogi, P. Burrato and G. Toscani (2015). Slip-rates of blind thrusts in slow deforming areas: Examples from the Po Plain (Italy), Tectonophysics, Volume 643, Pages 8-25, ISSN 0040-1951, http://dx.doi.org/10.1016/j. tecto.2014.12.007.

McNamara, D. E. and R. P. Buland (2004). Ambient Noise Levels in the Continental United States, Bull. Seism. Soc. Am., 94, 1517-1527.

MiSE-DGS-UNMIG, Ministero dello Sviluppo Economico - Direzione Generale per le Risorse Minerarie ed Energetiche (2001). Permesso 
di Ricerca SAN VINCENZO, http://unmig. sviluppoeconomico.gov.it/unmig/titoli/dettaglio. asp?cod $=510$.

MiSE-DGS-UNMIG, Ministero dello Sviluppo Economico - Direzione Generale per le Risorse Minerarie ed Energetiche (2006). Istanza di Concessione di Coltivazione in Terraferma - S. Alberto, http:/ / unmig. sviluppoeconomico.gov.it/dgsaie/istanze/dettaglio. asp? $\operatorname{cod}=158 \&$ numerofasi $=4$.

MiSE-DGS-UNMIG, Ministero dello Sviluppo Economico - Direzione Generale per le Risorse Minerarie ed Energetiche - Gruppo di lavoro CIRM (2014). Indirizzi e linee guida per il monitoraggio della sismicità, delle deformazioni del suolo e delle pressioni di poro nell'ambito delle attività antropiche, http:/ / unmig.sviluppoeconomico.gov.it/unmig/ agenda/upload/85_238.pdf.

Peterson, J. (1993). Observation and modeling of seismic background noise, U.S.G.S. Tech. Rept., 93-322, 1-95.

Pezzo, G., J. P. M. Boncori, C. Tolomei, S. Salvi, S. Atzori, A. Antonioli and R. Giuliani (2013). Coseismic deformation and source modeling of the May 2012 Emilia (Northern Italy) earthquakes. Seismological Research Letters, 84(4), 645-655.

PVO-PoValley Operations Pty Ltd (2014). SIA-Quadro progettuale, http://www.va.minambiente.it/itIT/ Oggetti/MetadatoDocumento/124979.

PVO/INGV-MI, PoValley Operations Pty Ltd / Istituto Nazionale di Geofisica e Vulcanologia - sezione di Milano (2015). Concessione di coltivazione idrocarburi "Sant'Alberto" - Studio di fattibilità per la realizzazione di una rete di monitoraggio microsismico e individuazione di eventuali faglie attive adiacenti o prossime al giacimento di San Pietro in Casale (BO), http:/ / www.va.minambiente.it/i

Rovida, A., R. Camassi, P. Gasperini and M. Stucchi (Eds.) (2011). CPTI11, the 2011 version of the Parametric Catalogue of Italian Earthquakes, Milano, Bologna, http:// emidius.mi.ingvit/CPTI/.

Schorlemmer, D., F. Mele and W. Marzocchi (2010). A completeness analysis of the National Seismic Network of Italy, J. Geophys. Res., 115, B04308, doi: 10.1029/2008JB006097.

${ }^{\star}$ Corresponding author: Simona Carannante Istituto Nazionale di Geofisica e Vulcanologia, sezione di Milano, Milan, Italy; email: simona.carannante@ingv.it 